\title{
Los objetos de la escritura en las obras de arte: acercamiento desde un enfoque de la Ciencia de la Información
}

\author{
Celso Martínez Musiño \\ Dokumenta Consultoría e Integraciones, México
}

REVIEW

\begin{abstract}
Resumen
En un periodo en el cual el uso de las Tecnologías de la Información y la Comunicación (TIC) permiten la conversión de los contenidos de objetos analógicos en digitales ponen en entredicho la permanencia de objetos que han sido tradicionalmente portadores de la escritura (e imágenes), como son los libros, las revistas y los periódicos, por mencionar algunos. A partir de esto se plantea como Objetivo: analizar la presencia de los libros, las revistas y los periódicos (imagen u objeto) en las obras de arte expuestas espacios cerrados, específicamente los museos. Método. Investigación descriptiva, documental y de campo, de carácter aproximativo. Resultados. Las tres piezas de estudio se encuentran o forman parte de las obras de arte, tanto en imagen o como objeto. Discusión. En el proceso de análisis conceptual, en combinación con los resultados de la investigación, se elabora el modelo de identificación de la escritura y símbolos escriturales en las obras de arte. Conclusiones. Los libros, no solo permanecen como imagen en las obras de arte, sino que se les reconoce como arte objeto, así también a los libros y las revistas. En conjunto, los tres elementos, entes de estudio, se les encuentran en alguna de las manifestaciones artísticas (pintura, la fotografía e instalaciones).
\end{abstract}

Palabras clave

Libros ; Revistas ; Periódicos ; Objetos escriturales ; Arte ; Ciencia de la Información

\section{The objects of the writing in works of art: approach from information science}

\begin{abstract}
In a period in which the use of Information and Communications Technology (ICT) allow the conversion of analog content into digital objects question the permanence of objects that have traditionally been carriers of writing (and images) such as books, magazines and newspapers, among others. From this arises the following Objective: to analyze the presence of books, magazines and newspapers (image or object) in the works of art displayed indoors, specifically museums.

Method. Descriptive, documentary, and field research, approximate nature. Results. The three parts of study are or form part of the works of art, both in image or object. Discussion. In the process of conceptual analysis, combined with the results of research, on develops the model writing and scriptural symbols in art. Conclusions. The books not only remain as an image in the works of art, but are recognized as art object, so books and magazines. Together, the three elements, entities of study, were found in one of the art forms (painting, photography and installations).
\end{abstract}

Keywords

Books ; Journals ; Newspapers ; Book-objects art ; Information Science

\section{Introducción}

En la época actual nos encontramos en una etapa de transición de la sociedad de la información a las sociedades del conocimiento, el libro impreso, como se ha conocido desde el Siglo XV está encontrando un nuevo competidor, complemento, o reemplazante según la óptica con que se mire, el libro electrónico. No obstante estos dilemas es posible encontrar imágenes del objeto libro (conjunto de hojas unidas de alguna manera, con sus respectivas tapas, o cubiertas, e información que lo identifica y lo distingue de otros) en las 
obras de arte en el Siglos XX y lo que llevamos del Siglo XXI. Además del libro como emblema gráfico hay otros dos elementos que permanecen en el imaginario colectivo, los periódicos y las revistas (publicaciones con contenidos varios y que se distinguen por un título colectivo y su publicación más o menos regular). A diferencia de los libros, estos dos elementos, y particularmente los periódicos, contienen gran parte de gráficos: fotos, juegos de destreza, caricaturas, esquemas y otro tipo de ilustraciones. Las revistas, por su parte, son predominantemente ilustradas, (cronografías, cronologías, fotos, esquemas y todos aquellos que competen a su perfil editorial).

Retomando, y regresando al interés por el análisis de los íconos de la escritura en las obras de arte, bien vale la pena mencionar que este estudio se incentivó a partir del desarrollo del proyecto Los objetos, las superficies y los visualizadores de la escritura (Martínez Musiño, 2015) y la redacción del documento ldentificación de la escritura en las obras de arte. En éste último se identificaron presencias escriturales en las obras de arte en el periodo del Siglo XI al Siglo XX. Durante el desarrollo de ambas pesquisas se observaron personas leyendo, sujetando o mostrando imágenes de objetos tradicionalmente aceptados como portadores o contenedores de la escritura (libros, periódicos y revistas, entre otros objetos). Por un lado, los libros han sido analizados en distintas áreas del conocimiento, la bibliología (Tagle, 2007; Barbier 2005; Chartier, 1997; Chivelet, 2003; Alturo i Penucho, 2003; Dahl, 1990), la bibliotecología, la historia intelectual, la industria editorial (Marsá, 2001), el diseño y la comunicación visual (Villanueva Segovia, 2008) por mencionar algunas. Por otra, parte los periódicos y las revistas son también el objeto de estudio de las ciencias de la comunicación, o bien la archivística, y recientemente por los diseñadores de páginas web, entre otras disciplinas.

Sin embargo, las imágenes de estos objetos, o los libros, las revistas y los periódicos, en un sentido estricto de su ubicación en espacios cerrados como los museos, no han sido tratadas por la Ciencia de la Información, especialmente como íconos en las obras de arte, aunque hay que puntualizar que sí hay estudios desde un enfoque bibliotecológico. A partir de la ciencia de la información buscamos estudio de las imágenes como objetos escriturales, según los siguientes hallazgos no se menciona en los dominios de la disciplina en cuestión expuestos por Birger Hjørland (2002). En cambio sí se menciona parcialmente el tema de las imágenes en los esquemas de clasificación que elabora Chaim Zins (2007) tanto en la recuperación de imágenes (sistemas de información), como en la recuperación de contenidos basada en imágenes (áreas de aplicación de la ciencia de la información), en las bases de datos bibliográficas, numéricas o de imágenes (sistemas y servicios de información electrónica), en el tratamiento de las imágenes (como formas de tratamiento de información primaria), también Michael Buckland (1999) trata las imágenes como complemento a la tradición documental y computacional de la ciencia de la información, pero nada concreto respecto al tópico propuesto en esta investigación.

Por otro lado, desde la ciencia bibliotecaria, sí hay iniciativas que abordan el estudio de las imágenes. Héctor Guillermo Alfaro López $(2009 ; 2014)$ ha abierto una línea de investigación en la cual plantea una lectura iconográfica argumentando que hoy en día estamos rodeados por una sociedad que crea, edita, publica imágenes y las comparte casi en todo momento. Así mismo este autor, en coordinación con Catalina Pérez Meléndez, (2014) han publicado el libro El Giro visual en bibliotecología: intersecciones de la información, la imagen y el conocimiento. En esta monografía comienzan a vislumbrarse vestigios que muestran el interés por el estudio de la escritura y las imágenes desde una óptica de la información y el conocimiento.

Si pensamos en una situación problemática de los objetos (o las imágenes de esos objetos) seleccionados para nuestro estudio se desprende que por mucho tiempo tuvieron su auge hasta que fue posible su conversión a formatos digitales. Mediante el desarrollo de herramientas de las TIC (las computadoras, las tablets, las laptops, los smartphones, entre otras) aparecen nuevas formas de edición, publicación y distribución de las publicaciones, los libros, las revistas y los periódicos (y otros documentos). Este es el dilema en el que se encuentran nuestros artefactos de estudio, o bien se encuentran aún en papel, bien en papel y formato electrónico, o en su defecto solo en esta última modalidad. Así podemos mencionar por ejemplo que el periódico The Independent este año 2016 se publicará solo digitalmente, corriendo la misma suerte de otros títulos de libros y publicaciones periódicas.

El enfoque con el que se aborda el artículo es desde la ciencia de la información, responsable de estudiar la fenomenología de la información, la cual se encarga de analizar -valga la redundancia- el concepto información: cómo se produce, cómo se organiza, quiénes y cómo la utilizan. Para ello, una definición amplia de este término es el conjunto de signos y símbolos que después de un proceso de análisis ayudan a la comprensión y la toma de decisiones. Por otra parte, traducido el interés por el análisis de los objetos escriturales, nos proponemos como objetivo: analizar la presencia de los libros, como imagen o como objeto, en las obras de arte, 
principalmente aquellas expuestas en espacios cerrados (museos). Para cumplir con nuestro cometido, la investigación se estructura de la siguiente manera: antecedentes; apuntes conceptuales: de la escritura al objeto de la ciencia de la información; método; resultados; discusión y conclusiones.

\section{Antecedentes}

Desde la historia primitiva del desarrollo, los seres humanos han tenido la necesitad de registrar, en principio, su vida cotidiana, por ejemplo la caza con la descripción de los elementos principales: el hombre y los animales. Para dicha secuenciación de hechos, se valieron de espacios y objetos tales como las paredes de las cavernas, las piedras y subsiguientemente artefactos como cántaros, platos e incluso la vestimenta. En una etapa posterior del desarrollo, las sociedades mesopotámicas, para atender requerimientos como el registro de la producción agrícola, las transacciones comerciales, algunos pasajes históricos, por mencionar algunos ejemplos, inventaron la escritura cuyo soporte principal fueron las tablillas de arcilla.

Además de utilizar las tablillas de arcilla, los egipcios exploraron las bondades del uso del papiro como soporte de la escritura. Este material requería un proceso de manufactura más o menos sencillo, cuya mayor durabilidad y manejabilidad superó la elaboración y uso de piezas de arcilla (etiquetas, tablillas, entre otras), estableciendo así una industria que trascendió fronteras. Los romanos adoptaron el papiro como soporte de la escritura, sin embargo, casi simultáneamente elaboraron otro material, el pergamino, como superficie de la escritura, encontrando en éste ventajas tales como manejabilidad, facilidad de escribir y reescribir. No obstante estas mejorías su costo era elevado. Ante los altos precios de los rollos de papiro y los pergaminos, nace en Occidente la explotación del papel, cuyo origen y secreto chino fue develado, lo cual provoco una demanda y una consecuente industria que permanece hasta nuestros días con múltiples usos.

Con el papel se crearon múltiples aplicaciones, las hojas, los naipes, el papel estraza, el cartón, y por supuesto, la preparación, la edición y la publicación de libros, periódicos, revistas (y otros objetos con mayor carga de imágenes que de escritura) y estos a su vez se establecieron como elementos de uso común. Así como el ser humano primitivo trataba de registrar visualmente su entorno, actualmente los artistas diseñaron e incluyeron imágenes que se convirtieron en signos "que mantiene una relación de semejanza con el objeto representado" (RAE, 2014), los libros no fueron la excepción, como se verá en los resultados de esta investigación, también es factible encontrar y reconocer los periódicos y las revistas. Concentrándonos en los antecedentes de los libros incluidos en las obras de arte, tenemos la pintura del Siglo XV la Madonna of the Magnificat de Sandro Boticceli en la cual la Madonna sujeta una pluma e insinuando continuar con la escritura en un libro abierto, o bien La Escuela de Atenas de Rafael en la cual, entre otros filósofos y pensadores, aparecen Platón y Aristóteles quienes cada uno de ellos sostienen un libro.

En el Siglo XVI, solo por mencionar algunos, artistas como Pinturicchio, Giovanni Bellini, Miguel Ángel, Tiziano, incluyeron en sus obras a los libros. En esta centuria pudiera sobresalir El bibliotecario (óleo sobre lienzo, 1566) de Giuseppe Arcimboldo quien representa ese retrato con solo libros y hojas (papel). Los libros también fueron motivo de inclusión en la plástica del Siglo XVII por Brueghel El Viejo, Nicolás Poussin, Aniello Falcone, entre otros. En la misma secuencia de mención de nombres virtuosos, en el Siglo XVIII encontramos a Goya, Mariano Salvador Maella, Pompeo Girolamo, Giovanni Paolo Pannini, etc., mientras que del Siglo XIX nos remitimos a Gustave Courbet, Alfred Roll, Valeriano Domínguez Becquer, Ignacio León Escosura. De este último, además de libros, es posible encontrar imágenes de periódicos en su obra Estudio del pintor. En cuanto al Siglo XX podemos referirnos a las pinturas de Albert Gleizes, Enric Solbes, Cecilio Pla, Gino Severini, por mencionar algunos virtuosos, o bien a las fotos de Nicolás Muller. En términos de consolidación de símbolos escriturales podemos afirmar que los libros no solo fueron objetos de uso cotidiano, sino que se erigieron como piezas de indiscutible valor para el artista. En párrafos posteriores de este estudio encontrará que no solo hay pinturas con imágenes de libros, revistas o periódicos, sino fotos, arte-objeto o instalaciones.

\section{Apuntes conceptuales: de la escritura al objeto de la Ciencia de la Información}

En esta sección, se parte de la descripción de los conceptos en dos rubros, el primero incluye términos concebidos para un público general y propuestos por la Real Academia Española (en adelante RAE), y en segunda instancia, éstos conceptos se enlazan con los términos especializados, símbolo e información, con la lingüística y la Ciencia de la Información. Por escritura se entiende como el "Sistema de signos utilizados para escribir..." (RAE, 2014). Desglosando este enunciado, para el concepto signo se han seleccionado solo aquellas 
variantes concernientes con la escritura. Entonces, por signo se comprende: a) como la "señal o figura que se emplea en la escritura y en la imprenta"; b) la "Unidad mínima de la oración, constituida por un significante y un significado; y, c) la "marca gráfica, sin ser letra o número, se emplea en la lengua escrita para contribuir a la correcta lectura e interpretación de palabras y enunciados; por ejemplo los signos de puntuación” (RAE, 2014).

Cuando seleccionamos y enumeramos las definiciones de signo, se desprenden otros términos afines tales como la letra, el número, la palabra, la puntuación, y el texto. Por letra, se comprende a "cada uno de los signos gráficos que componen el alfabeto de un idioma" (RAE, 2014, p. 1329); por número, se entiende como el "signo o conjunto de signos con que se representa el número" o, como la "expresión de cantidad con relación a su unidad" (RAE, 2014). Por palabra se precisa como la "unidad lingüística, dotada generalmente de significado, que se separa de las demás mediante pausas potenciales en la pronunciación y blancos en la escritura" (RAE, 2014). Por puntuación se admite como el "Conjunto de los signos ortográficos utilizados para puntuar" (RAE, 2014, p. 1818). Y, por texto, se acepta como el "enunciado o conjunto coherente de enunciados orales o escritos" (RAE, 2014).

La conveniencia de incluir los términos signo y símbolo se debe a que representan múltiples expresiones, sus definiciones dependen de cada área del conocimiento. Los conceptos son atendidos por la sociología, la psicología, las artes gráficas, el psicoanálisis, las matemáticas, las Ciencias de la Comunicación y la Ciencia de la Información, entre otros. Para fines de nuestra investigación, por signo se acepta como el "Objeto, fenómeno o acción que, por naturaleza o convención, representa o sustituye a otro" (RAE, 2014), mientras que por símbolo, cuyo origen griego symboleion que hace referencia a dos mitades de un mismo objeto (Schneider, 2011) y "se caracteriza por una relación de semblanza...entre significante y significado" (Weller, 2010), se entiende como la:

Representación gráfica invariable de un concepto de carácter científico o técnico, constituida por una o más letras u otros signos no alfabetizables que goza de difusión internacional, y que, a diferencia de la abreviatura, no se escribe con punto propuesto; p. ej. N, He, km... (RAE, 2014, p. 2013).

No obstante esta definición, nos adherimos al argumento de Mario Consens (2006) cuando afirma que "Los símbolos imitan una realidad, pero nunca son iguales a ella". Después de incluir las definiciones conceptuales asociadas a la escritura, a manera de conclusión de este sub-apartado y aludiendo a fuentes especializadas en lingüística, aceptamos la definición que propone Ignace J. Gelb cuando afirma que el concepto en cuestión es "...un sistema de intercomunicación humana por medio de signos convencionales visibles" (1982) y complementamos con lo que se concibe en la Encyclopedia of linguistics (2005): la escritura es distinguida de otras formas de representación pictórica en la que se relaciona directamente a la expresión lingüística. En relación a las funciones de la escritura, nos adherimos a la propuesta de Florian Coulmas (1991) quien en The writing systems of the world la insinúa como soporte de la memoria y una expansión del rango comunicacional, que la concibe como un medio de transmisión de mensajes, permite una regulación social y cumple funciones interaccionales y estéticas.

\section{1 ¿Qué se entiende como objetos escriturales?}

Para fines de nuestro estudio se comprende que los objetos escriturales son aquellos objetos que funcionaron, o se reconocen, como contendores de la escritura y que, por su valor cultural, social o económico, incidieron significativamente en las sociedades y su desarrollo. Por lo tanto, dichos objetos pueden ser representados e identificados gráficamente como símbolos. Por ejemplo, las tablillas de arcilla, los rollos de papiro, los libros manuscritos, los libros impresos, los periódicos, las revistas y actualmente, los libros electrónicos, entre otros. Estos objetos fueron asimilados por las personas y las sociedades, construyéndolos así, dentro del imaginario, individual y colectivo, como símbolos. Dichos símbolos, reincidentemente en las obras de arte, son asumidos por distintos artistas, y comprendidos y digeridos por las personas interesadas en su apreciación. En consecuencia, como iconografía de los objetos escriturales en el arte se expresa como el (los) objetos(s) que contuvieron, o contienen, alguna forma de escritura y dada su importancia histórica, cultural, social o económica, ha sido apropiada visualmente y expresada en alguna tipo de manifestación artística. 


\subsection{La información como objeto de estudio de la Ciencia de la Información}

La pregunta ¿qué es información? no es nueva, desde la aparición de los fenómenos de la explosión de la información, o de la era de información, hasta nuestros días -la sociedad de la información-, estudiosos de distintas disciplinas o áreas del conocimiento han tratado de contestarla. La información se relaciona con múltiples aspectos de la sociedad, a lo largo de la historia su manifestación para cada generación dice mucho acerca de la actitud de las sociedades en términos de control, la cultura, la política, el conocimiento y la educación (Weller, 2007). Nuestro estudio puede hacerse desde variadas posiciones, disciplinas o perspectivas, no obstante esta multiplicidad de opciones la investigación se realiza principalmente desde el contexto de la ciencia de la información, así es que comenzaremos a dilucidar el concepto información.

S. G. Faibisoff \& D. P. Ely (1976) indican que además de contener datos, la información se encuentra constituida por ideas, símbolos o conjunto de símbolos con un significado potencial. Los autores consideran, además que la información reduce incertidumbres y ayuda en la toma de decisiones, es decir, apoyan en la resolución de problemas. Esos dilemas y necesidades a resolver se manifiestan en los individuos. La información es algo aprendido, son hechos recogidos, así como una medida del contenido de un mensaje y puede ser un enunciado, una opinión, puede tratarse de hechos, conceptos o ideas, o de una asociación de declaraciones, opiniones o ideas. La información está estrechamente asociada con el conocimiento una vez que ha sido asimilada, correlacionada y entendida (Keenan \& Johnson, 2000).

La información tiene características intrínsecas que han sido estudiadas por décadas en campos tales como las ciencias bibliotecaria y de la información, específicamente en organización de la información, clasificación, catalogación, indización, por mencionar algunos (Zhang \& Benjamin, 2007). Sheila Webber (2003) por su parte, en un sentido semántico, considera que la información es significativa, tiene un tópico, y es inteligencia o instrucción acerca de algo o de alguien; mientras que, en el contexto de la sociedad de la información, constituye una nueva era -la era de la información, la información en la sociedad de la información o la información en la transición hacia las sociedades del conocimiento-. En esta etapa de metamorfosis se centra nuestra investigación, si por una parte la información se conforma de los datos, y por otra, como ya hemos vertido, la escritura son signos y símbolos, esta es la vinculación encontrada para justificar el estudio de la escritura y los objetos escriturales en las obras de arte.

\section{Método}

Estudio descriptivo cuyo procedimiento consiste en investigación documental (visita a bibliotecas) y estudio de campo (museos, exposiciones). Después de seleccionar los libros, las revistas y los periódicos como objetos de la escritura se procedió a identificar aquellas obras de arte en las cuales aparece alguno de estos símbolos. Posteriormente se procedió a su análisis para la redacción de los resultados y las conclusiones. Alcances y limitaciones. La investigación debe considerarse como primera aproximación al tema; las obras de arte son una selección que comprenden el periodo del Siglo XX al Siglo XXI, principios de 2016; el tipo de manifestación de arte: pintura, foto, arte objeto e instalaciones.

\section{Resultados}

En este apartado se presenta una selección de obras en las cuales se observan los libros, las revistas o los periódicos como imagen, o como objeto, ya sea en la pintura, la fotografía, o bien como libro arte objeto, e instalaciones. Esa colección, a lo largo del tiempo, se ha convertido como íconos en la sociedad, tanto así que es posible reconocerlos como signo o símbolo de la creación humana. Se comienza con el libro que es el objeto que más tiempo se ha erigido predominantemente como aquel elemento que ha resguardado la escritura como soporte de la memoria y difusión de la cultura, enseguida se abordan los periódicos y las revistas.

\subsection{El libro en la pintura, en la fotografía e instalaciones}

Así como existe la naturaleza muerta en la pintura, es posible encontrar obras que solo contienen objetos inanimados, tales como lápices, hojas con bocetos y libros. Por ejemplo Enric Solbes en La taula [sic] del taller, pieza elaborada en acrílico y collage, presenta los elementos mencionados, incluso en el libro se identifica el autor y el título: "KANDINSKY" "PUNTO Y LINEA SOBRE EL PLANO", mientras que en una hoja se observa el boceto del mismo cuadro. Esta obra fue expuesta en el Museo Pablo Serrano del Instituto Aragonés de Arte y Cultura Contemporáneos (IAACC) el año 2015. Por otra parte, los libros también se encuentran presentes en la 
fotografía. Por ejemplo, en la Escuela Judía de Nicolás Muller identificamos al menos nueve infantes y un profesor húngaros, cada quien con su respectivo libro (Tabla 1); la foto fue exhibida en La Lonja de Zaragoza en 2015.

Tabla 1. El libro en la pintura y en la fotografía

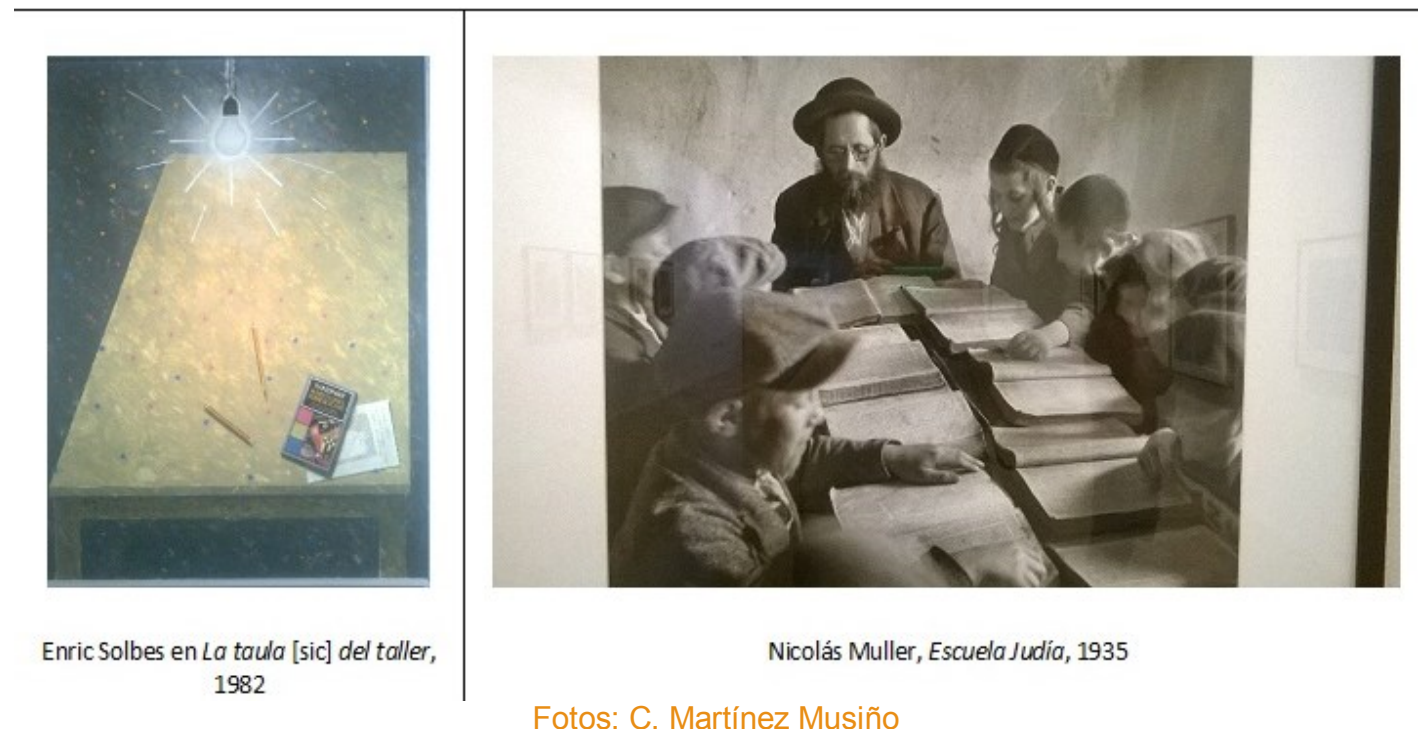

\subsection{El profesional del libro: el editor}

Desde la invención de los tipos móviles en la imprenta de Gutemberg las labores del editor se fueron profesionalizando, incluso su rol social cobro importancia tal que algunos personajes dedicados a esas actividades fueron inmortalizados en pinturas, por ejemplo El editor Eugène Figuiére de Albert Gleizes, pieza elaborada en óleo sobre tela que muestra al personaje rodeado de libros. Algunos de éstos con sus datos bibliográficos, por ejemplo, un libro contiene "PAUL PORT" "GUSTAVE KAHN", otro expresa "DU CUBISME", uno más transcribe "POEME ET DRAME H.M. BARZ...". En otros ejemplos se lee "Rythmes simultanés", o bien, en un libro se reproduce "JAQUES NAYRAL" "LE SCULPTEUR de GLOIRE y en otro se enuncia "LES MURMUR”. Finalmente, otros tantos ejemplares incluyen datos sobrepuestos y otros textos ilegibles. Además, en el ángulo superior de la pintura se observa parte de un reloj con números romanos: "II, III, IV, V, VI, VII"; el cuadro incluye la firma del artista. (Tabla 2). La obra ha sido presentada en el Museo de Arte Moderno (MUNAL) bajo el título colectivo de la exposición Los Modernos en 2016.

Tabla 2. Detalles de la pintura de Albert Gleizes, El editor Eugène Figuiére, 1913

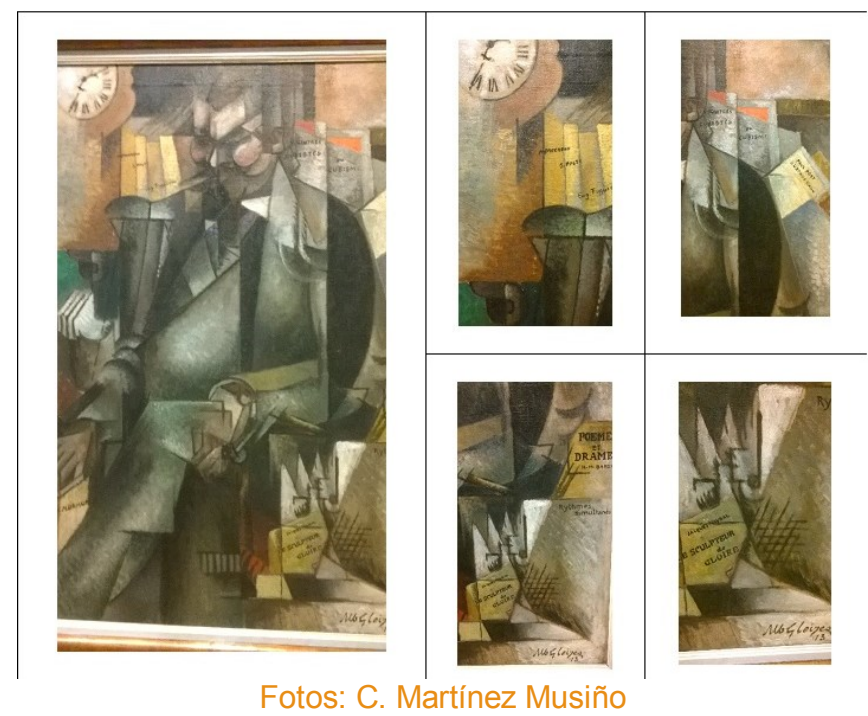




\subsection{Estructura del libro e imaginario en el arte}

Composición de los libros. A lo largo de la historia de los libros, desde los manuscritos hasta los impresos, estos objetos se han ido modificando y consolidando su estructura paulatinamente hasta tener como resultado, tanto física como esquemáticamente la suma de sus partes tal cual los conocemos en la actualidad. Por ejemplo, a grandes rasgos, los libros se conforman de un conjunto de hojas, cosidas, pegadas, engrapadas o sujetas de alguna otra forma, cuentan con una cubierta anterior y otra posterior (en ocasiones con solapas) y lomo, principalmente; además tienen hojas guarda. En relación con la composición esquemática de contenidos, los libros tienen por lo general, portada, contraportada, índice, prólogo (o prefacio) y el cuerpo de la obra, en ocasiones incluyen índices analíticos, onomásticos, por mencionar algunos elementos.

La forma y la estructura de los libros no solo han quedado fijos en el imaginario de las personas y reconocidos socialmente, sino que también en el interés de los artistas. Así, en consecuencia, podemos encontrar obras plásticas no solamente personas leyendo sino que el creador, la creadora, la artista Pilar Álvarez, ha consignado como títulos de su producción: Prólogo, Capítulo y Epílogo (Tabla3). En cada una de las imágenes es posible observar a una persona sentada tomando un libro en tres poses diferentes en las cuales, mientras que se recorre visualmente esta trilogía, el lector, en el Prólogo aparece sentado, inmutable. En el Capítulo el mismo personaje se va acomodando conforme avanza en la lectura Finalmente, en la parte del Epílogo se nota una introspección mayor del lector, se muestra muy cómodo y con mayor cercanía entre su mirada y el libro. Estas pinturas fueron expuestas bajo el tópico colectivo Pigmentados en el Centro Joaquín Roncal en 2015.

Tabla 3. El libro como símbolo y objeto de lectura en la obra de Pilar Álvarez

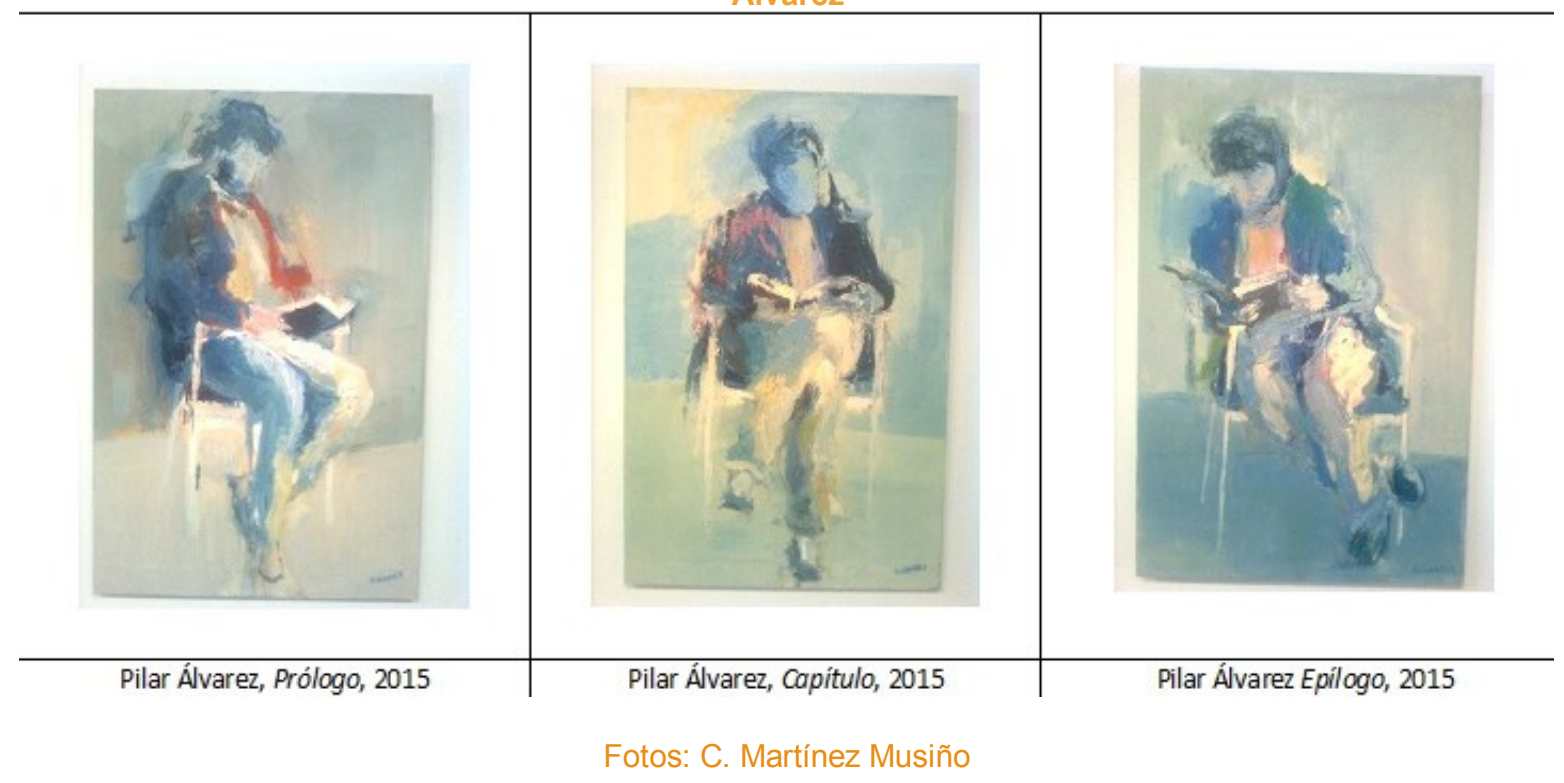

\subsection{Libro arte objeto}

El libro ha sido expuesto: a) como unidad; b) a manera de conjunto y en acompañamiento con otras piezas similares; c) como parte de la conformación de bibliotecas (un artista le llama librería), o bien; d) acompañado de otros objetos. Para el primer caso encontramos El libro de las lamentaciones de José Antonio Hernández Vargas, perteneciente a la colección del Instituto Nacional de Bellas Artes. Mientras que para el segundo ejemplo tenemos la obra Cromo $x x$ de Guillermo Álvarez Charvel que es un conjunto de libros, en su mayoría abiertos, con sus hojas dobladas y acomodados para presentarlos a manera de instalación. Por otra parte, para el tercer tipo es la instalación Las palabras son demasiado concretas de Eugenio Ampudia conformado según la cédula de identificación por una librería con libros manipulados y pantallas electrónicas. Este caso no solo es una colección de libros, sino que algunos de sus ejemplares fueron intervenidos por el artista. En la parte del lomo, se les realizó una ranura y se les adaptaron unas pantallas electrónicas. En una de éstas se incluye el texto con efecto de transición: "je est un...". Los tres casos mencionados se presentaron en el Museo de Arte Carrillo Gil (Tabla 4). Finalmente, para la cuarta tipología, los libros acompañador con objetos diversos, podemos 
mencionar la obra Love sounds (sonidos de amor) de Jaume Plensa, compuesta por un estuche de nylon blanco con forma de libro (contiene un Disco Compacto con fragmentos del sonido de la circulación de la sangre y cinco impresiones digitales). En la cubierta del libro se lee "Love Sounds", en letra cursiva y en el interior "JAUME PLENSA", mientras que el Disco también está rotulado y las impresiones digitales contienen el nombre del artista, la fecha, la hora y otros datos (Plensa, Jaume, 2004).

Tabla 4. Libros intervenidos

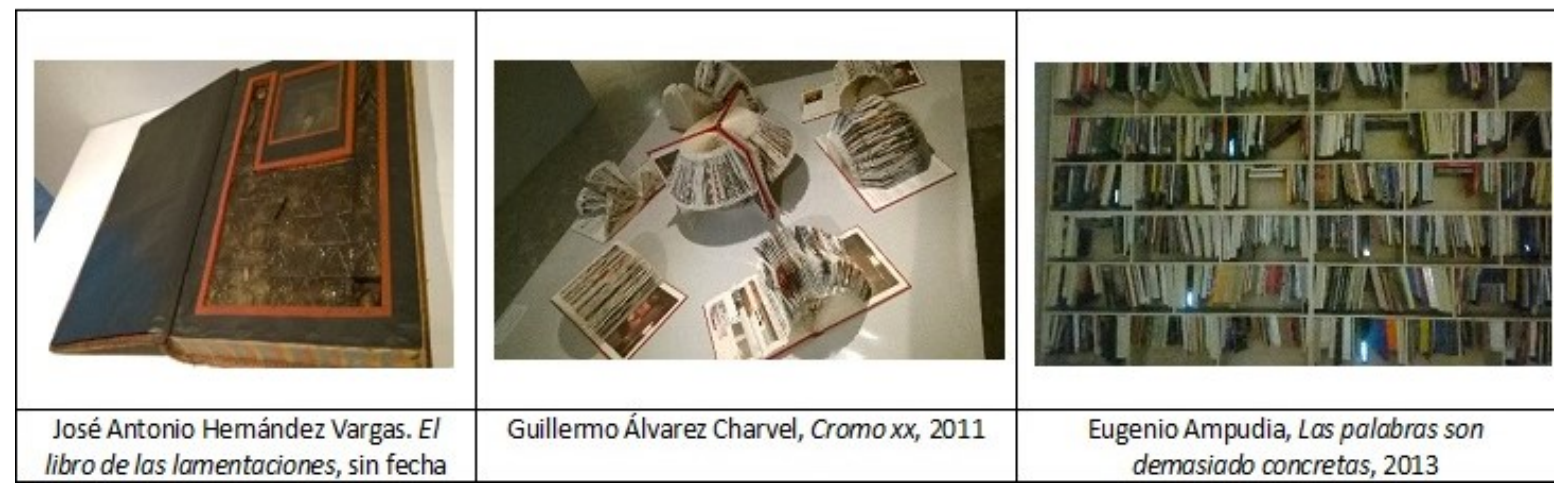

Fotos: C. Martínez Musiño

Los libros se han conformado como íconos de la escritura, la inclusión, la organización, el resguardo y la difusión del conocimiento, además, como lo hemos constatado también como signo gráfico de distintas manifestaciones del arte. El libro, no solo se presenta en la pintura, también como arte objeto, sino como un elemento al cual se le interviene, añadiendo, sustrayendo alguna de sus partes o bien presentándolo como un conglomerado (conjunto de libros) e incluso como bibliotecas completas que ocupan un espacio en lugares de exhibición (museos o galerías de arte). En estos espacios cerrados es más frecuente ver al libro arte objeto, al libro arte objeto, los libros de viajes que en conjunto, con otras denominaciones, se les denomina libro alternativo (Martínez Musiño, en prensa).

\subsection{Los periódicos intervenidos, en partes para collage, o en instalaciones.}

Desde la aparición del periódico era frecuente observar su distribución a un ejército de medios de transporte trasladando grandes paquetes, debidamente flejados, a los distintos puntos de venta, o en su defecto, previa suscripción, presenciar la visita de los servicios de mensajería (motocicleta, bicicleta, principalmente) para la entrega matutina de los diarios que mantenía al día, informativamente hablando, a sus lectores. Sin embargo, esas formas de transporte han ido disminuyendo en la medida que los periódicos se editan en formato digital y se consultan a través de dispositivos electrónicos (computadoras, tablets, smartphones, por mencionar algunos dispositivos). No obstante esa transición de las conformaciones analógicas a digitales, se observa aún una convivencia de formatos. El periódico tiene su importancia y valor históricos, además de la consulta de primera mano se crearon repositorios especializados, hemerotecas, en los cuales se organizan, se resguardaban, y se les ofrece mantenimiento para su preservación. Ahora, además de esos espacios los encontramos también en los museos como pieza de exhibición en las siguientes modalidades: 1) sin intervención; 2) con intervención del artista; 3) como fragmentos de una obra, y; 4) como aquellos incluidos en instalaciones.

En el primer grupo, piezas sin intervenidas, es menester referirse a la exposición Enrique Metinides. El hombre que vio demasiado presentada en el Foto Museo Cuatro Caminos en 2016 en la cual se presentan las portadas de periódicos de tipo sensacionalista (La Prensa, Zócalo, Crimen y Alarma) acompañadas de otros objetos, por ejemplo tarjetas de identificación de ex-policías o ex-agentes de investigaciones del mismo ramo; ninguno de esos ejemplares fue intervenido (Foto 1). 
Foto 1. La prensa, Alarma y Magazine de policía, 1960-1990

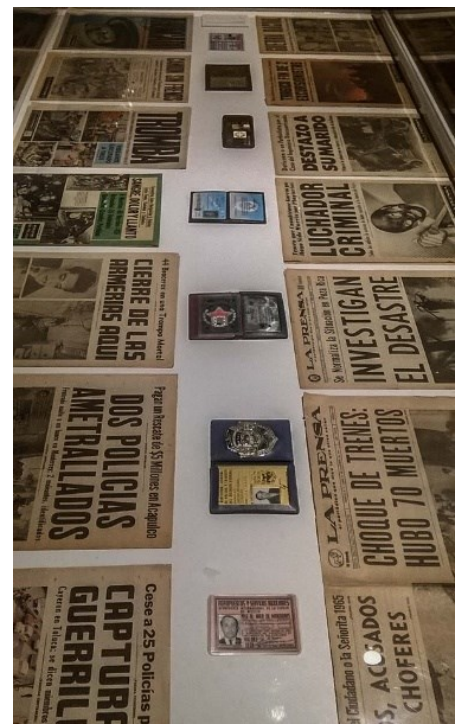

Foto: C. Martínez Musiño

En la segunda categorización, obras intervenidas, encontramos la colección de periódicos intermediados por artistas varios y expuestos en el Museo de El Carmen bajo el tema "La Poesía vista por el Arte", siendo precisamente, valga la redundancia, Periódico intervenido el título asignado a cada una de las piezas exhibidas. En la Tabla 5 se han seleccionado tres artistas: César Rangel, Armando Romero y Roberto Parodi. El primero utiliza carbón, el segundo acrílico y el último óleo; todos trabajan sobre una portada distinta del Periódico MILENIO. Además de observarse el título del periódico seleccionado y el texto respectivo de cada uno de éstos, un artista (Parodi) opta por solo incluir un rostro humano, otro dibuja dos personas en aparente diálogo, más cuatro rostros de perfil y escribe su firma: "romero". El último, Rangel, añade palabras o textos: "FLOTANTE", "AGUA", ... o bien la fecha de elaboración de la obra, "MAYO DE 2014".

Tabla 5. Periódicos intervenidos, 2014.

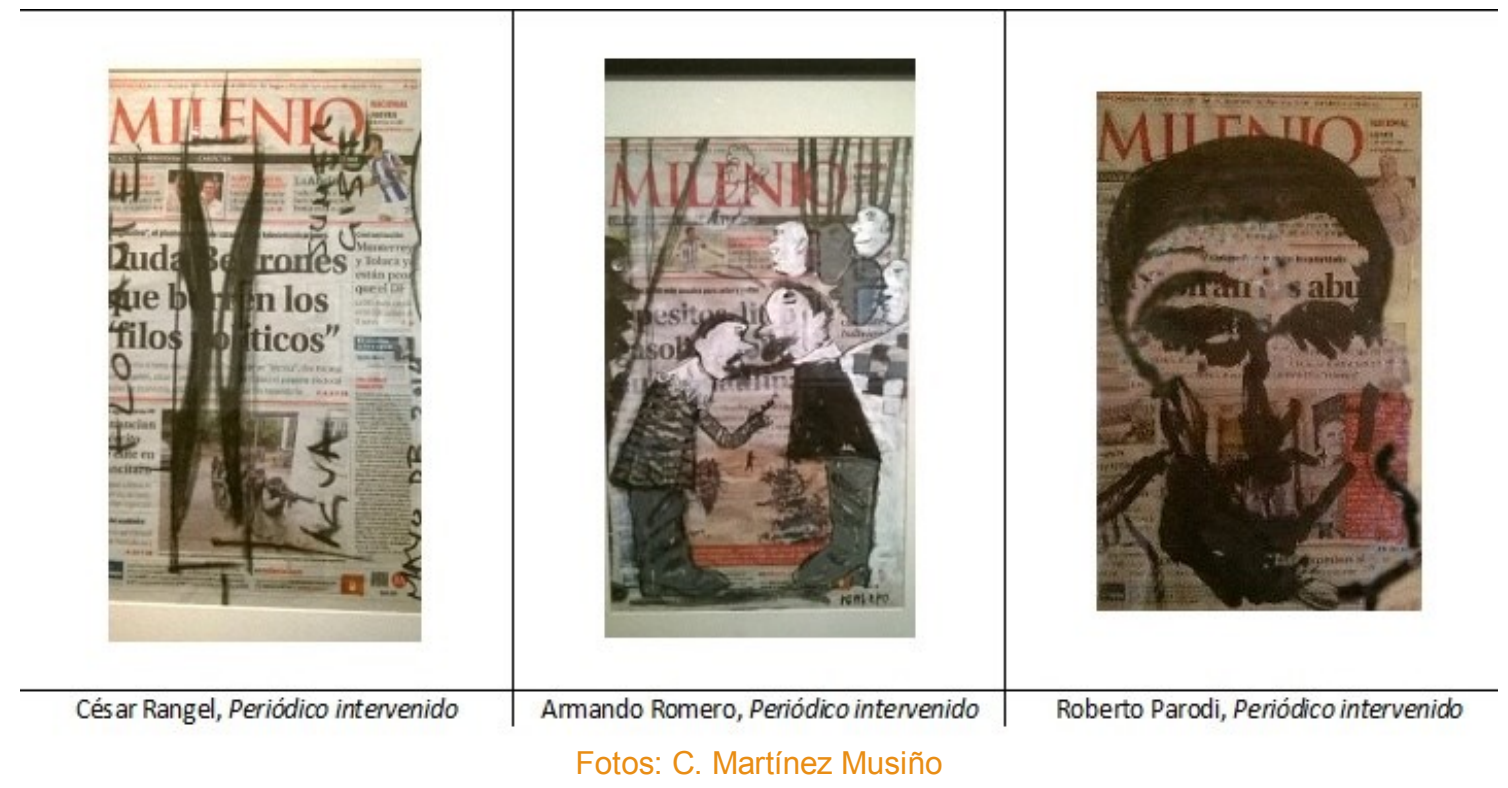

En cuanto a la tercera categoría, fragmentos de periódicos en una obra, específicamente en la pintura de Dimitri Perdikidis presentó el collage sobre tablero Sin título, también, en el Museo Pablo Serrano del Instituto Aragonés de Arte y Cultura Contemporáneos (IAACC) en 2015. En dicha pieza, se integran partes de un diario circunscrito en un rombo y este a su vez en un marco en color negro (Tabla 6). El título de una nota periodística destaca: “...meine Seele su retten...”, más los contenidos parciales de una página (ilegibles). 
Tabla 6. Parte de una nota periodística en un collage

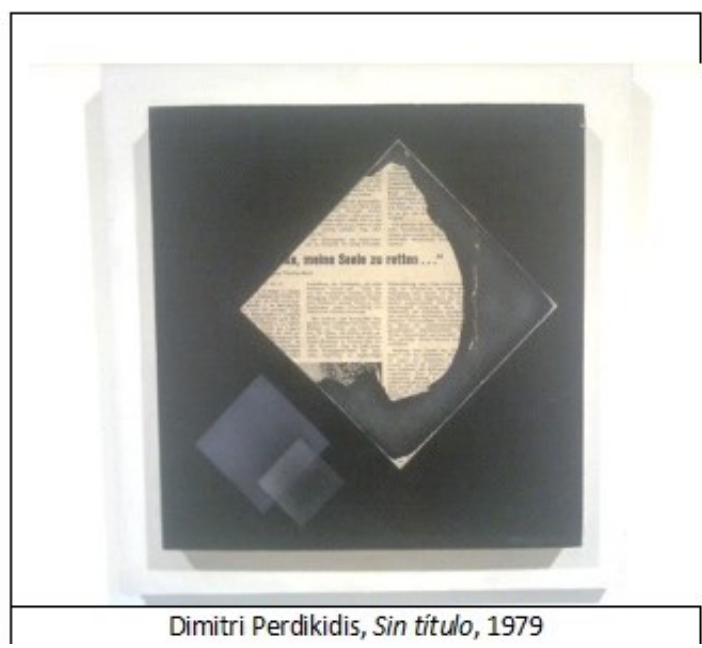

Foto: C. Martínez Musiño

En relación al último grupo, los periódicos en las instalaciones, en el Museo Júmex mencionaremos la obra Lección sobre la Historia del Arte No. 7 de Luis Kamnitzer, la cual consiste en la presentación de diez proyectores de diapositivas sobre distintos objetos. Uno de los proyectores se encontraba en al menos uno de los tres paquetes de periódicos debidamente sujetos, cada uno de estos cuenta con una altura aproximada de un metro y diez centímetros (Foto 2).

Foto 2. Detalle de la instalación Lección sobre la historia del arte No. 7 de Luis Kamnitzer, 2000.

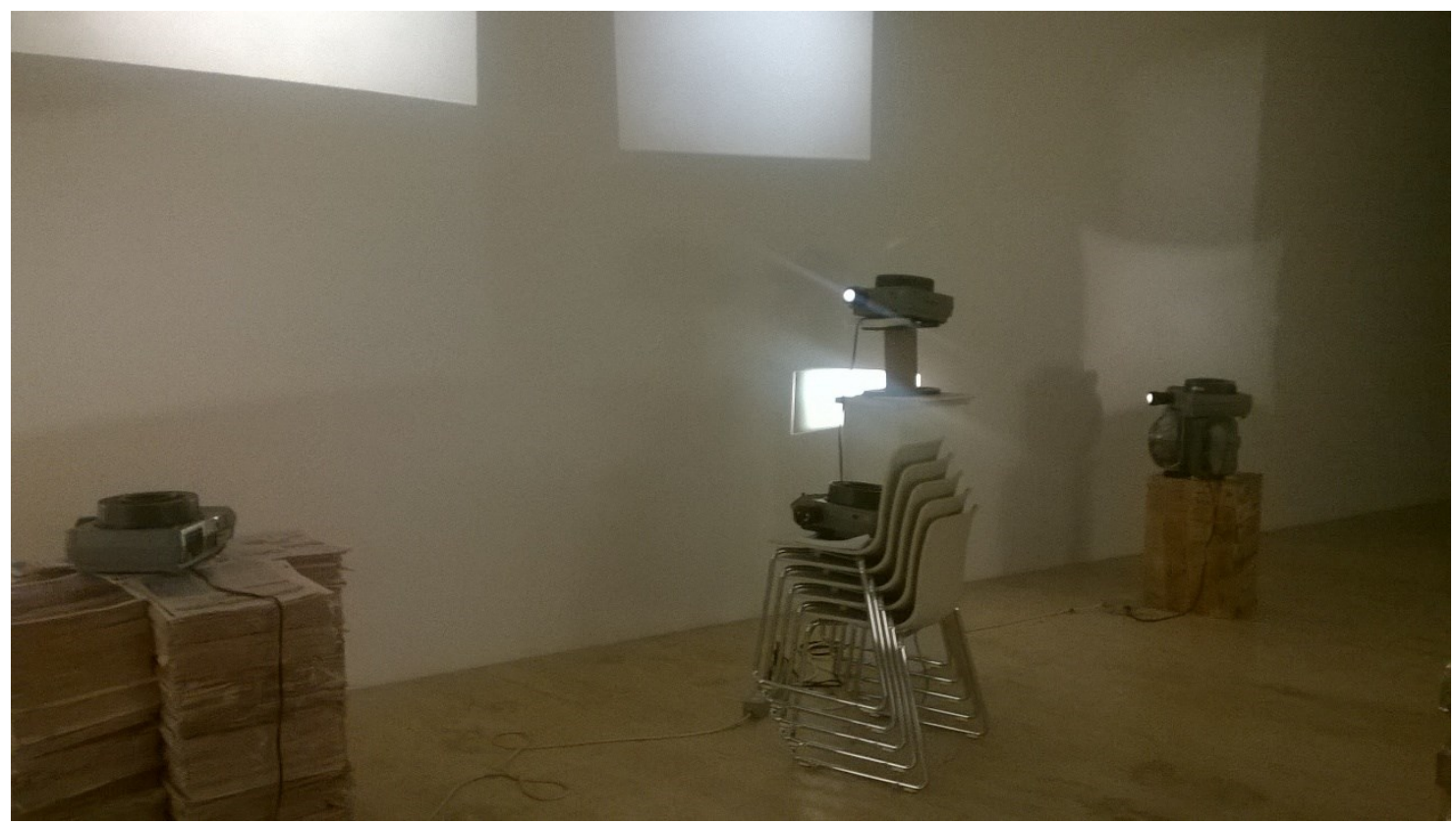

Foto: C. Martínez Musiño

\subsection{Las revistas en instalaciones y exposiciones temáticas}

Las revistas tienen la particularidad de incluir múltiples artículos, noticias, publicidad y otros elementos, se distinguen, además, por un título distintivo que agrupa los diferentes documentos, se publican periódicamente y los hay de incontables tipos y temas, por ejemplo: especializadas y de divulgación, o bien magazines que contienen temas de interés general, es decir, destinadas a un público amplio. Este tipo de publicaciones, al igual que los libros y los periódicos, también están inmersas en un cambio radical, además de encontrarlas en papel, 
también se editan y publican en formato digital y su consulta requiere de algún dispositivo electrónico; hay títulos que solo se publican en formato electrónico.

Las revistas, al igual que los periódicos, se resguardan en organismos en los cuales hay grandes flujo de información que requieren de procesos de organización, mantenimiento y almacenamiento especializados, nos referimos a las hemerotecas públicas o privadas. Las revistas publicadas en papel, también, las encontrarlos en otros espacios cerrados como los museos y galerías de arte. Por ejemplo, en 2016, en el Museo Júmex se exhibe la obra Evidencias de una farsa de Carla Zaccagnini, la cual comprende dos revistas completas, la primera "TIME" presenta un mapa de Brasil, mientras que la segunda "The Economist", incluye la leyenda "Brazil Takes off' en la cual se representa también una imagen de la figura de Cristo Redentor en Río de Janeiro (Foto 3).

Foto 3. Carla Zaccagnini, Evidencias de una farsa, 2011

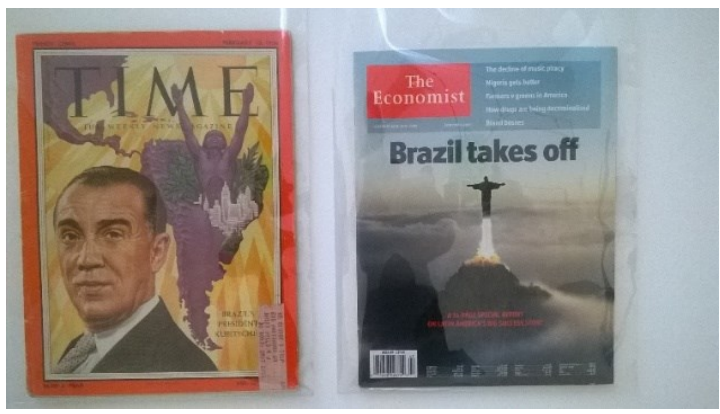

Foto: C. Martínez Musiño

Además de la presentación de las revistas en la modalidad instalación también estas publicaciones se incluyen en fotografías, así podemos mencionar Un primer encuentro con la imagen de Isabel Guerra. En su obra, impresión sobre papel Hahnemühle, texturizado, 100\% algodón y libre de ácido, presenta la efigie de una niña atenta hojeando una revista; esta foto se presentó en la Galería Ibercaja Patio de la Infanta (Zaragoza) en 2015. Otro ejemplo, es el evento en el cual se expusieron tanto las portadas de revistas como algunas fotografías es Coming into Fashion: un siglo de fotografía en Condé Nast. En la exposición se presentaron algunos números seleccionados de la revista especializada en moda Vogue en el Museo Franz Mayer en 2015 (Tabla 7). En algunas fotos es posible identificar elementos gráficos de objetos escriturales como aquella de Inez \& Vinoodh, Vogue Francia de octubre de 2002, en la cual se observa una persona sujetando un paquete de libros y cuadernos.

Tabla 7. Exposición Coming into Fashion: un siglo de fotografía en Condé Nast, 2015
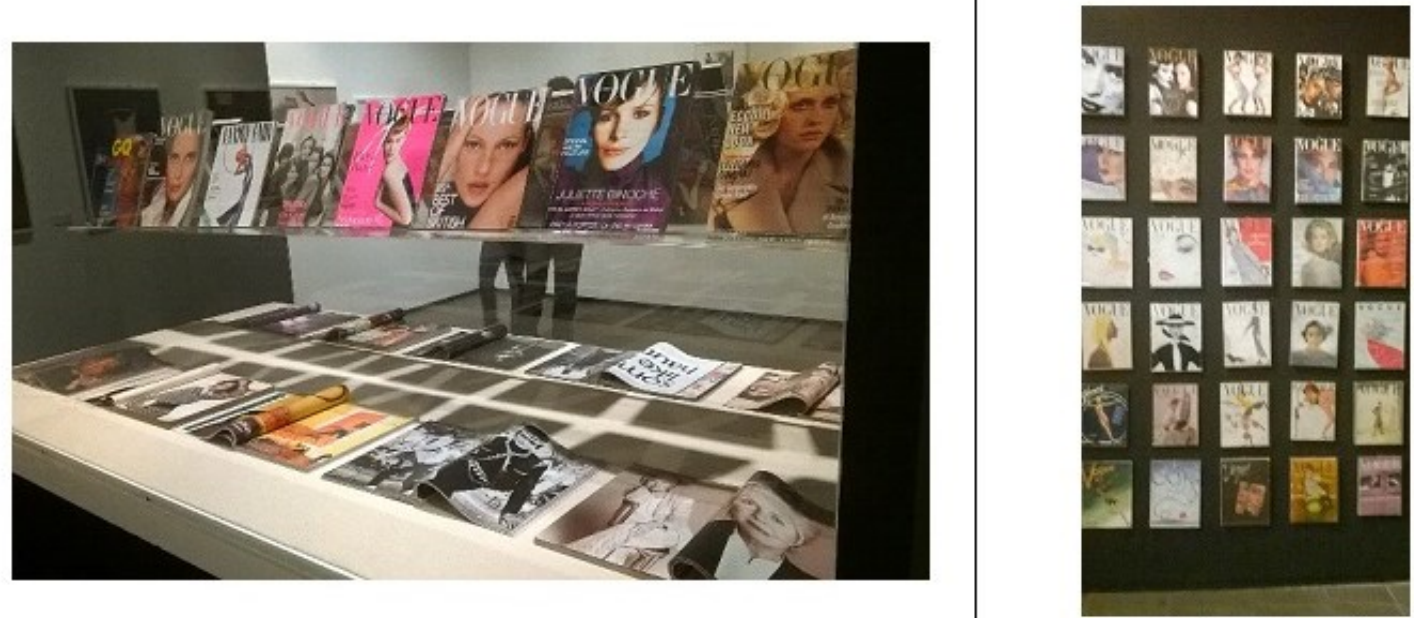
Como conclusiones de este apartado tenemos que: a) por una parte, la escritura en las obras de arte se manifiesta de distintas formas (tipo escritura), color, material utilizado; b) por otro lado, los soportes escriturales pueden ser los mismos objetos (libros, revistas, periódico), o bien utilizados como símbolos dentro de la obra (pintura); c) los libros y los periódicos, pueden ser intervenidos por el artista; d) aunque en la selección de obras no se encontraron vestigios de intervención artística en las revistas, no indica que sea una conclusión definitiva, y; e) algunas obras de arte se intersectan con otras manifestaciones como la literatura (la poesía, por ejemplo).

\section{Discusión}

Como resultado de la delimitación conceptual del término escritura, la búsqueda de una definición de los objetos escriturales y la vinculación con el término información se ha diseñado el modelo de identificación de la escritura y los símbolos escriturales en las obras de arte, en adelante El Modelo (Figura 1). En El Modelo, se aprecia la suma de las letras, los números, las palabras, los signos de puntuación, el texto. Como resultado de esas adiciones se tienen los signos o símbolos que conforman la escritura. Entonces, si la escritura está conformada por signos y símbolos, y también la información parte de estos dos elementos, la Ciencia de la Información puede abordar el análisis de las imágenes como símbolos escriturales que a través del tiempo requirieron de contenedores (libros, revistas, periódicos), cuyas representaciones gráficas son reconocidas, casi inmediatamente.

Figura 1. Modelo de identificación de la escritura y símbolos escriturales en las obras de arte

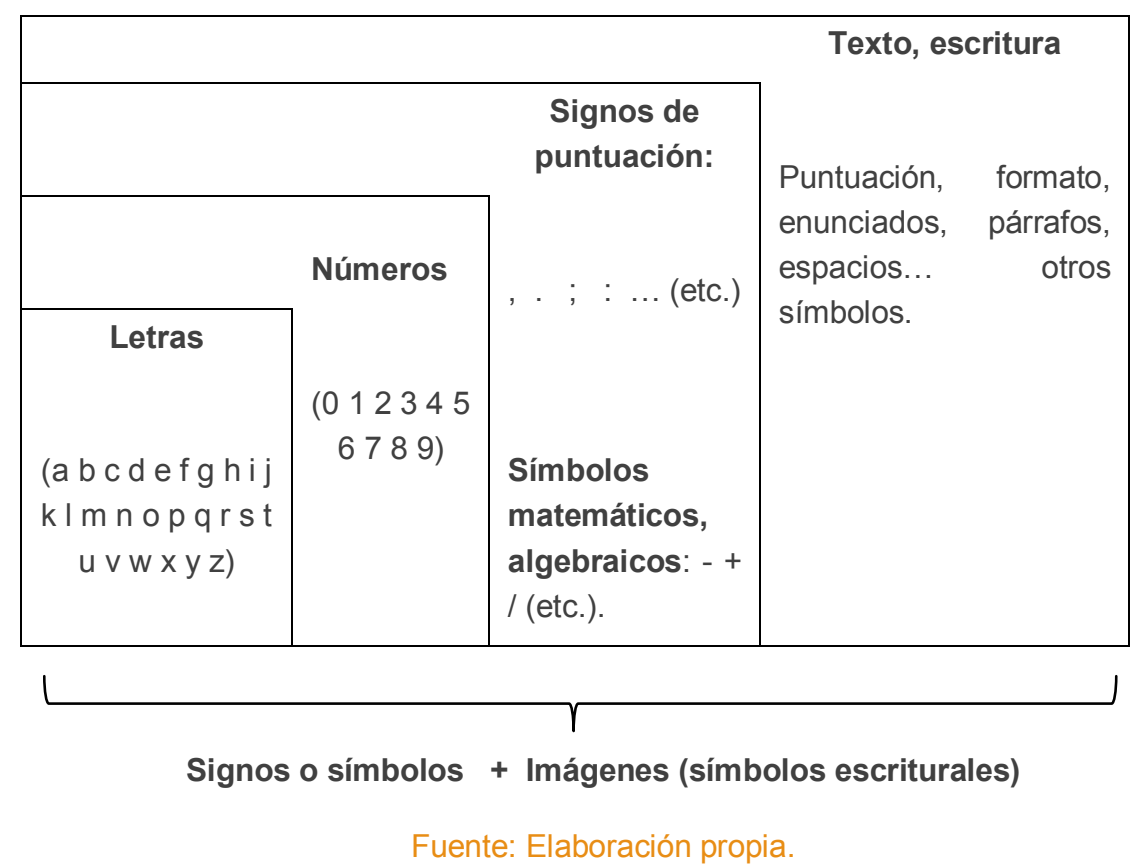

En relación a las definiciones de escritura y su vínculo con el objeto de estudio de la Ciencia de la Información, podemos argumentar que si nos apoyamos en El Modelo es posible: a) encontrar el nexo signo y símbolo, tanto en la escritura como en la información (objeto de estudio de la Ciencia de la Información); b) asumir que los objetos de la escritura, también son símbolos, y en tanto que están compuestos de datos, pueden ser objeto de estudio de la Ciencia de la Información; c) identificar muestras escriturales (letras, números, palabras, texto) e imágenes (libro, periódico y revista) que, los distintos sectores sociales y dada su importancia adquirida a través del tiempo, son asumidas, diseñadas, recreadas o intervenidas para ser parte de distintos productos artísticos (pintura, foto, arte objeto), o bien conformar, en conjunto con otros objetos, instalaciones.

No obstante que esta investigación es de carácter descriptiva-exploratoria, apegándose a El Modelo, es posible profundizar en el tema desde varias aristas y enumerar algunos elementos para realizar futuras pesquisas, por ejemplo: 1) ahondar en cada tipo de manifestación artística estudiada en este artículo; 2) aplicar El Modelo en 
otras disciplinas del arte (escultura, cine, arquitectura, por mencionar algunas); 3) inspeccionar otros periodos distintos al tratado en este documento, tanto en el pasado como en el futuro. También, continuando en el mismo orden de ideas, es factible; 4) seleccionar y analizar otros objetos de la escritura con mayor carga de imágenes y menor cantidad de vestigios escriturales (por ejemplo, fotos, pósteres, postales, entre otros). Además, en la medida que la ciencia de la información tiene características intradisciplinarias, según George Adam Holland (2008), o multidisciplinarias y transdisciplinarias, y reflexionando acerca de algunos resultados, también es posible: 5) realizar estudios informétricos (registrar la aparición y frecuencia de palabras); 6) consumar análisis del discurso, tanto de los resultados de este artículo como aquellos obtenidos de futuras pesquisas; 7 ) ejecutar análisis bibliométricos (identificar los autores títulos, fechas, etc. de los objetos escriturales que aparecen en las obras de arte; por mencionar otras líneas de investigación).

\section{Conclusiones}

A lo largo de la historia del ser humano, y específicamente cuando la palabra requirió la escritura como mensaje, se utilizaron múltiples superficies u objetos, ya sea con fines de resguardo de la memoria, para fines administrativos, o para la difusión de la cultura, entre otros. Entre los objetos más significativos, ya sea por su importancia cultural, económica y su uso social destacan las tablillas de arcilla, los rollos de papiro, los pergaminos y, por supuesto, todos aquellos elaborados con base en el papel. De este material podemos mencionar todas las variantes de libros (manuscrito e impreso), las revistas y los periódicos, solo por enumerar algunas piezas dignas representantes de la escritura.

Según los resultados de nuestra investigación podemos concluir que: a) los libros, prácticamente aparecen acompañados de textos, ya sea los propios, o bien con adiciones de palabras o leyendas por parte del artista; b) los periódicos difícilmente se disocian de los textos, bien sea de notas publicadas, o bien por palabras e imágenes, o sólo imágenes del creador; c) las revistas se distinguen más en las fotos y en las instalaciones que en las pinturas, en éstas son pocas las veces que interviene el artista, es decir, no hay una sobre exposición de imágenes o textos en las piezas originales.

Además, podemos confirmar que las obras artísticas pueden estar compuesta tanto por evidencias de escritura como de objetos escriturales y el común denominador de las imágenes, o símbolos escriturales, en los tres elementos estudiados (libro, periódico y revista) es la asociación al texto del mismo objeto, también podemos observar que las piezas analizadas hay una tendencia a utilizarlas como arte objeto o bien como parte integral de instalaciones.

Por otra parte, en la medida que la escritura son signos y símbolos, y éstos a su vez son componentes de la información, entonces es posible la apertura de estudios a partir del enfoque de la ciencia de la información y estudiar otros símbolos con mayor carga de imágenes y menor presencia de la escritura, como las fotos, los carteles y las tarjetas postales. Tanto las piezas estudiadas en este artículo como las que se mencionan en este párrafo para pesquisas futuras se encuentran en transición de formatos, del físico al electrónico.

Finalmente, concluimos de manera general que la escritura requirió, demanda y necesitará de alguna forma de visualización: un objeto, una superficie o algún espacio como el museístico. En relación a los objetos analizados en este artículo, particularmente, podemos afirmar que, si los circuitos de producción, distribución y adquisición de los libros, las revistas y los periódicos tuvieron actores como editores, puntos de venta tradicionales, hay que añadirles como destinatario, también, a los artistas y como lugar de exhibición, los museos y galerías de arte.

\section{Referências}

Alfaro López, H. G. (2009). Introducción a la lectura de la imagen. México: UNAM.

Alfaro López, H. G. (2014). Bibliotecología y lectura de la imagen. Investigación Bibliotecológica, 28(64), 7-12. Recuperado de http://www.scielo.org.mx/pdf/ib/v28n64/v28n64a1.pdf

Alfaro López, H. G. \& C. Pérez Meléndez, coords. (2014). El Giro visual en bibliotecología: intersecciones de la información, la imagen y el conocimiento. México: UNAM, Instituto de Investigaciones Bibliotecológicas y de la Información. Recuperado de http://132.248.9.34/cuib/1701193.pdf

Alturo i Perucho, J. (2003). Història del llibre manuscrit a Catalunya. Catalunya: Generalitat de Catalunya. 
Barbier, F. (2005). Historia del libro. Madrid: Alianza.

Buckland, M. (1999). The landscape of information science: The American Society for Information Science at 62. Journal of the Association for Information Science and Technology, 50(11), 970-974.

Chartier, R. (1997). The End of the Reign of the Book. SubStance, 26(1), 9-11.

Chivelet, M. (2003). Historia del libro. Madrid: Acento.

Consens, M. (2006). De símbolos e interpretaciones (sobre decodificadores y exégetas). Revista de Arqueología Americana, (24), 7-28.

Coulmas, F. 1991. The writing systems of the world. Oxford/Brasil, Oxford/Blackwell.

Dahl, S. (1990). Historia del libro. Madrid: Alianza.

Encyclopedia of linguistics (2005). New York: Fitzroy Dearborn.

Faibisoff, S., \& D. P. Ely (1976), Information and information needs. Information Reports and Bibliographies, 5(5), 2-16.

Gelb, I.J. (1982). Historia de la escritura. $2^{a}$ ed. Madrid: Alianza.

Hjørland, B. (2002). Domain analysis in information science: eleven approaches-traditional as well as innovative. Journal of documentation, 58(4), 422-462.

Holland, G.A. (2008). Information science: an interdisciplinary effort? Journal of Documentation, 64(1), 7-23.

Keenan, S., \& S. Johnson (2000). Concise dictionary of library and information science. (2a ed.). London: Bowker Saur.

Marsá, M. (2001). La imprenta en los Siglos de oro. Madrid: Laberinto.

Martínez Musiño, C. (2015). Los soportes, las superficies y los visualizadores de la escritura: enfoques y materiales.

DataGramaZero - Revista de Informação, 16(6). Recuperado de

http://eprints.rclis.org/28796/1/Lossoportes\%2Clas\%20superficiesylosvisualizadoresdelaescritura.pdf

Martínez Musiño, C. (en prensa). Aproximación a los objetos escriturales en el arte: del libro convencional al libro alternativo.

Plensa, J. (2004). Jaume Plensa: libros, grabados y múltiples sobre papel = books, prints and multiples on paper: $1978-2003$. Valencia: Fundación César Manrique.

Real Academia Española [RAE] (2014). Diccionario de la lengua española. (23a ed.). Madrid: Real Academia Española.

Schneider, V. S. (2011). El simbolismo universal del icono. Imagens da Educação, 1(3), 39

Tagle, M. (2007). Historia del libro: texto e imágenes. Buenos Aires: Alfagrama.

Villanueva Segovia, M. (2008). Introducción a la historia del libro infantil ilustrado en Occidente: de los manuscritos medievales a la industria editorial. México: La autora. (Tesina: Licenciatura en Diseño y comunicación visual-UNAM). Recuperado de http://132.248.9.195/ptd2009/febrero/0639776/Index.html

Webb, S.P. (1997). Information. En Feather J., \& P. Sturges (Eds.). International encyclopedia of information and library science. London: Routledge. pp. 184.

Webber, S. (2003). Information science in 2003: a critique. Journal of Information Science, 29(4), 311-330

Weller, T. (2007). Information history: Its importance, relevance and future. ASLIB Proceedings: New Information, 59(4/5), 437448.

Weller, T. (2010). Símbolos, imágenes, rituales: el lenguaje simbólico del poder en la Europa del Antiguo Régimen. Memoria y civilización, 13, 9-33.

Zhang, P., \& R. I. Benjamin, (2007). Understanding information related fields: a conceptual framework. Journal of the American Society for Information Science and Technology, 58(13), 1934-1947.

Zins, C. (2007). Classification schemes of Information Science: Twenty-eight scholars map the field. Journal of the American Society for Information Science \& Technology, 58(5), 645-672. 


\section{Agradecimientos}

Un especial agradecimiento al Consejo Nacional de Ciencia y Tecnología (México) por el apoyo financiero para el desarrollo del proyecto posdoctoral Los soportes, las superficies y los visualizadores de la escritura: enfoques y materiales del cual forma parte esta investigación. A la Universidad de Zaragoza por las facilidades materiales otorgadas para realizar una estancia de investigación. Al Dr. Francisco Javier García Marco por su asesoría, hospitalidad y finas observaciones del proyecto.

\section{Datos del autor}

Celso Martínez Musiño

Diplomado en Acción y Desarrollo Cultural por el Museo Nacional de San Carlos, y Espacio Espiral (México). Maestro y Licenciado en Bibliotecología por El Colegio de México y la Universidad Nacional Autónoma de México (UNAM), respectivamente. Doctor por la Universidad de Zaragoza y la UNAM. Actualmente se desempeña como investigador y consultor.

celsommm@yahoo.com.mx

Recibido - Received: 2016-02-25

Aceptado - Accepted: 2016-05-07

\section{(cc) $\mathrm{Br}$}

This work is licensed under a Creative Commons Attribution 4.0

United States License.

\section{ULLS DDof}

This journal is published by the University Library System of the University of Pittsburgh as part of its D-Scribe Digital Publishing Program and is cosponsored by the University of Pittsburgh Press. 